\title{
Improvement of left ventricular function after percutaneous coronary intervention in patients with stable coronary artery disease and preserved ejection fraction: Impact of diabetes mellitus
}

\author{
Malgorzata Sikora-Frac, Beata Zaborska, Pawel Maciejewski, \\ Andrzej Budaj, Bronislaw Bednarz \\ Department of Cardiology, Center of Postgraduate Medical Education, \\ Grochowski Hospital, Warsaw, Poland
}

\begin{abstract}
Background: Many patients with stable coronary artery disease (CAD) have no visual segmental wall motion abnormalities and a left ventricular (LV) ejection fraction $(L V E F) \geq 50 \%$ at rest despite significant coronary artery stenosis. Here, the aim was to determine the impact of percutaneous coronary intervention (PCI) on LV function assessed by enhanced echocardiography in patients with stable CAD with or without diabetes mellitus type 2 and a preserved LVEF.

Methods: Sixty-six consecutive patients with CAD and LVEF $\geq 50 \%$, admitted to the hospital for planned coronary angiography, were prospectively assessed. PCI was performed for coronary artery stenosis $>70 \%$. CAD extent was assessed using SYNTAX and EXTENT scores. To assess LV function, $L V E F$, global longitudinal strain (GLS), and LV peak systolic myocardial velocity (S') were measured and Tei index was calculated before and 3 months after PCI.

Results: Before PCI, LVEF, GLS, and Tei index were significantly worse in diabetic patients. LV functional indices improved significantly after PCI in all patients $(p<0.001)$. Multivariate linear regression analyses were performed to evaluate the impact of selected factors on LV function after PCI expressed as changes $(\Delta)$ of LVEF, GLS, S', and Tei index. LV function improvement expressed as $\triangle G L S$ was associated only with SYNTAX score. Higher SYNTAX scores were related to greater GLS improvement ( $\beta=0.003,95 \%$ confidence interval: 0.0004-0.005; $p=0.02$ ).

Conclusions: Percutaneous coronary intervention significantly improved LV function in diabetic and non-diabetic CAD patients with preserved LVEF. Enhanced echocardiography allowed an assessment of subtle changes in LV function. (Cardiol J 2021; 28, 6: 923-931)
\end{abstract}

Key words: coronary artery disease, left ventricular function, percutaneous coronary intervention, echocardiography, diabetes mellitus

\section{Introduction}

Stable coronary artery disease (CAD) is one of the most common cardiovascular diseases. Acute and chronic myocardial ischemia leads to systolic and diastolic left ventricular (LV) dysfunc- tion resulting in the development of heart failure [1]. Percutaneous coronary intervention (PCI) is a widely used invasive treatment for CAD that eliminates symptoms, improves LV function and quality of life, and, in selected groups of patients, reduces the incidence of death $[2,3]$. However,

Address for correspondence: Malgorzata Sikora-Frac, MD, PhD, Grochowski Hospital, Center of Postgraduate Medical Education, Department of Cardiology, ul. Grenadierów 51/59, 04-073 Warszawa, Poland, tel: +48 225152660 , fax: +48 2251526 71, e-mail: msikora-frac@wp.pl

Received: 8.04.2019 Accepted: 9.06.2019 Early publication date: 27.06.2019

This article is available in open access under Creative Common Attribution-Non-Commercial-No Derivatives 4.0 International (CC BY-NC-ND 4.0) license, allowing to download articles and share them with others as long as they credit the authors and the publisher, but without permission to change them in any way or use them commercially. 
an optimal revascularization strategy for patients with diabetes mellitus type $2(\mathrm{DM})$ remains under discussion $[4,5]$. Most patients with stable CAD have no visual segmental wall motion abnormalities and an LV ejection fraction (LVEF) $\geq 50 \%$ at rest despite significant coronary artery stenosis. Limited data are available concerning the effects of elective $\mathrm{PCI}$ on LV function in patients with stable CAD (especially in diabetic patients), without myocardial infarction (MI), and with preserved LVEF. The value of single echocardiographic parameters in the assessment of LV function before and after PCI has been analyzed [6-9]. Standard echocardiography with an LVEF assessment does not reflect all aspects of LV systolic function. The use of advanced echocardiographic techniques including tissue Doppler echocardiography and LV strain measurement (e.g. global longitudinal strain [GLS]) enables the demonstration of LV systolic dysfunction despite preserved LVEF. Information obtained through advanced echocardiography may allow clinicians to decide whether to perform PCI in stable CAD patients with preserved LVEF and comorbid DM. The study aims were to determine the impact of PCI on LV function assessed by enhanced echocardiography in patients with stable $\mathrm{CAD}$ and preserved LVEF and evaluate the impact of $\mathrm{DM}$ on $\mathrm{LV}$ systolic function in patients with $\mathrm{CAD}$ before and after PCI.

\section{Methods}

\section{Study population}

Two hundred and fourteen consecutive patients were prospectively selected with symptomatic CAD without acute coronary syndrome in whom coronary angiography and PCI were performed. Patients with prior MI, symptomatic heart failure, segmental LV wall motion abnormalities, an LVEF $<50 \%$, arrhythmias, or poor acoustic windows were excluded from the study. To exclude acute ischemia, electrocardiography was performed in each patient prior to coronary angiography and compared with previous electrocardiograms (ECG). Patients were referred for coronary angiography by treating physicians and then qualified for PCI according to the European Society of Cardiology Guidelines for CAD [2]. All patients included in our study complained of cardiac ischemic pains (CCS I-III). Myocardial ischemia was confirmed by resting ECG (chronic ST-changes) or ambulatory ECG (Holter) monitoring (myocardial ischemia during normal activities) and/or treadmill exercise testing (ST-segment abnormality). Diagnostic tests were conducted in 40 patients (21 CAD patients, 19 diabetic CAD patients).

Percutaneous coronary intervention was considered successful when Thrombolysis in Myocardial Infarction (TIMI) grade 3 flow and residual stenosis $<20 \%$ were achieved [10]. The decision concerning PCI and use of coronary stents was left to the treating cardiologists. Coronary angiography was recorded in digital form and assessed for ongoing study by an independent invasive cardiologist blinded to the patient history and ECG and echocardiographic data. CAD extent was assessed using SYNTAX [11] and EXTENT [12] scores.

N-terminal pro B-type natriuretic peptide, fasting blood glucose, creatinine, lipids, glycated hemoglobin concentrations, and glomerular filtration rate were assessed before the angiography was performed. To exclude DM, glucose tolerance tests were performed in patients without DM.

\section{Echocardiography}

Two-dimensional echocardiography with LV systolic and diastolic function assessments were performed. The first echocardiographic examination was performed before PCI $(<12 \mathrm{~h})$ in all patients who qualified for the study. The second echocardiographic examination was performed in all patients included in the study 3 months after the last PCI. Echocardiography was performed in the standard parasternal and apical views using a VIVID 9 (GE Medical System, Horten, Norway; 1.7-3.3-MHz transducer) and VIVID 4 (GE Medical System, Haifa, Israel; 1.5-2.5-MHz transducer) devices. All images were stored digitally for later analysis. LV function was expressed as LVEF, LV GLS, LV S', and Tei index. The Tei index was calculated as a sum of isovolumetric contraction time and isovolumetric relaxation time divided by $\mathrm{LV}$ ejection time as described by Tei [13]. LVEF was calculated using the modified Simpson method [14].

Apical four- and two-chamber and long-axis views were used for quantification of LV GLS by automated function imaging of two-dimensional speckle tracking analysis. All analyzed images were recorded with a frame rate $>55$ frames per second. Data were subsequently transferred for offline analysis using EchoPack Sw Only BT version 110.0.x (GE Medical System). For each of three views, mean longitudinal strain was calculated according to current standards [15]. LV GLS was calculated as the arithmetical mean of these three values. The division of LV into 17 segments was applied and presented graphically in the form of curves and bullseye plots (Fig. 1A, 1B). Territorial 


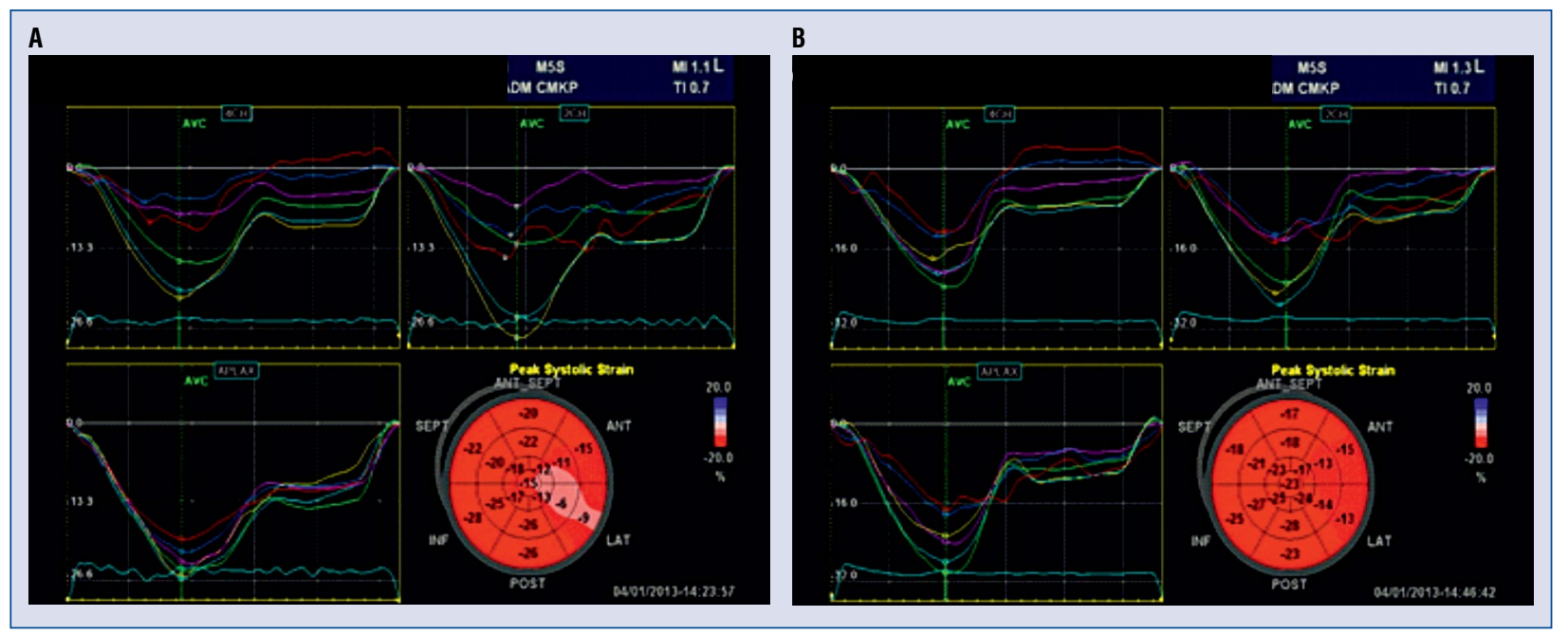

Figure 1. Assessment of global longitudinal strain with automated function imaging before percutaneous coronary intervention (PCI) (A) and after $\mathrm{PCl}$ for circumflex coronary artery (B). The polar maps show the improvement in segmental longitudinal strain in the mid and apical anterior segments and basal, mid, and apical lateral segments.

longitudinal strain (TLS) was calculated based on perfusion territories of the three major coronary arteries in a 17 -segment LV model by averaging all segmental peak systolic strain values within each territory [15]. For comparison with the angiographic findings, segments were correlated with the arterial supply as follows: basal anterior and anteroseptal, mid-anterior and anteroseptal, apical anterior, septal and apex were assigned to the left anterior descending (LAD) coronary artery distribution; basal inferoseptal and inferior, mid-inferoseptal and inferior, and apical inferior were assigned to the right coronary artery (RCA); and basal inferolateral and anterolateral, midinferolateral and anterolateral, and apical lateral were assigned to the left circumflex artery (LCX).

S' was assessed from the apical four- and twochamber view for basal segments septal, lateral, anterior, and inferior LV wall by pulsed tissue Doppler echocardiography. The average of these four basal velocities was used to calculate mean basal S'. Three consecutive beats were measured and averaged for all S' measurements.

\section{Statistical analysis}

The statistical analysis was preceded by an analysis of the group size. The sample size of patients in the study group was estimated based on the differences between S' and GLS values before and after PCI. Based on available literature, the minimum clinically meaningful differences for S' and GLS values before and after PCI were $0.7 \pm 1.1$ $\mathrm{cm} / \mathrm{s}[4,6]$ and $-2.5 \pm 3 \%[16,17]$, respectively. To prove the impact of $\mathrm{PCI}$ on $\mathrm{LV}$ function with a $5 \%$ level of significance and ensure that the power of the test was $80 \%$, to detect these differences, the minimum number of patients enrolled to this study should be 43 and 26 for S' and GLS, respectively. The data are expressed as mean value \pm standard deviation or median value (interquartile range) for continuous variables and frequency tables for discrete parameters. Mean values were compared with the t-test or the nonparametric Mann-Whitney $\mathrm{U}$ test. Proportions were compared using the $\chi^{2}$ test. Medians were compared with the Kruskal-Wallis test. Multivariate linear analyses were performed to evaluate the impact on LV function after PCI, expressed as changes of GLS, S', and Tei index between the measurements before and after PCI ( $\Delta$ GLS, $\Delta \mathrm{S}^{\prime}, \Delta$ Tei index). The correlation between the statistically significant parameters and the analysed parameters (GLS, S', Tei index) was expressed by the $\beta$ coefficient with a $95 \%$ confidence interval (CI). For $\mathrm{p}$ values $>0.1, \beta$ coefficient and $\mathrm{CI}$ were not indicated. $\mathrm{P}$ values $<0.05$ were considered significant. The Spearman correlation coefficients were calculated to assess the relationship between LV GLS and SYNTAX and EXTENT scores. Statistical analysis was performed using Stata version 10 .

\section{Results}

\section{Clinical data}

Of the 214 patients screened, 66 were enrolled in the study (34 with DM); the other 148 subjects 
Table 1. Demographic and clinical characteristic of the study population.

\begin{tabular}{|c|c|c|c|c|}
\hline Parameter* & $\begin{array}{l}\text { All patients } \\
\quad(n=66)\end{array}$ & $\begin{array}{c}\text { CAD + DM } \\
(n=34)\end{array}$ & $\begin{array}{c}\text { CAD } \\
(n=32)\end{array}$ & $\begin{array}{c}P(C A D+D M \\
\text { vs. CAD) }\end{array}$ \\
\hline Age [years] & $67 \pm 8.2$ & $67 \pm 8.7$ & $66.2 \pm 7.7$ & NS \\
\hline \multicolumn{5}{|l|}{ Sex: } \\
\hline Female & $23(35 \%)$ & $12(35 \%)$ & $11(34 \%)$ & NS \\
\hline Male & $43(65 \%)$ & $22(65 \%)$ & $21(66 \%)$ & NS \\
\hline BMI $\left[\mathrm{kg} / \mathrm{m}^{2}\right]$ & $29.3 \pm 4.0$ & $30.4 \pm 4.0$ & $28.2 \pm 3.7$ & 0.05 \\
\hline Current smoking & $12(18 \%)$ & $6(18 \%)$ & $6(19 \%)$ & NS \\
\hline Smoking cessation & $27(48 \%)$ & $14(48 \%)$ & $13(48 \%)$ & NS \\
\hline Hypertension & $59(89 \%)$ & $33(93 \%)$ & $26(81 \%)$ & NS \\
\hline DM duration [years] & - & $6 \pm 3.2$ & - & - \\
\hline $\mathrm{TC}[\mathrm{mg} / \mathrm{dL}]$ & $175.1 \pm 38.2$ & $171.3 \pm 39.8$ & $179.2 \pm 36.5$ & NS \\
\hline LDL-C [mg/dL] & $95.8 \pm 35.5$ & $88.8 \pm 3.0$ & $103.3 \pm 31.6$ & NS \\
\hline TG [mg/dL] & $136.4 \pm 63.8$ & $157.8 \pm 75.1$ & $113.8 \pm 38.7$ & 0.01 \\
\hline $\mathrm{HDL}-\mathrm{C}[\mathrm{mg} / \mathrm{dL}]$ & $49.2 \pm 13$ & $45.6 \pm 11.5$ & $53.1 \pm 13.6$ & 0.05 \\
\hline $\mathrm{GFR}>60 \mathrm{~mL} / \mathrm{min} \times 1.72 \mathrm{~m}^{2}$ & $20(30.3 \%)$ & $9(25 \%)$ & $11(34.3 \%)$ & NS \\
\hline NT-proBNP (pg/mL), median (min, $\max )$ & $145(73,273)$ & $136(64,293)$ & $151(104,238)$ & NS \\
\hline \multicolumn{5}{|l|}{ Medication: } \\
\hline ACEI or ARB & $52(79 \%)$ & $29(85 \%)$ & $23(72 \%)$ & NS \\
\hline BB & $63(95 \%)$ & $31(91 \%)$ & $32100 \%)$ & NS \\
\hline ASA & $66(100 \%)$ & $34(100 \%)$ & $32(100 \%)$ & NS \\
\hline Clopidogrel & $65(98 \%)$ & $33(97 \%)$ & $32(100 \%)$ & NS \\
\hline Statins & $59(89 \%)$ & $28(82 \%)$ & $31(97 \%)$ & NS \\
\hline \multicolumn{5}{|l|}{ DM treatment: } \\
\hline Diet & - & $5(15 \%)$ & - & - \\
\hline Diet + OAD & - & $24(70 \%)$ & - & - \\
\hline Diet + OAD + insulin & - & $5(15 \%)$ & - & - \\
\hline $\mathrm{HbA}_{1 \mathrm{c}}[\%]$ & - & $6.81 \pm 0.94$ & - & - \\
\hline
\end{tabular}

${ }^{*}$ Continuous variables are presented as mean \pm standard deviation and categorical variables are presented as number (percentage). CAD coronary artery disease; DM - diabetes mellitus type 2; NS - statistically nonsignificant; BMI - body mass index; TC - total cholesterol; LDL-C - low density lipoprotein cholesterol; TG — triglycerides; HDL-C — high density lipoprotein cholesterol; GFR - glomerular filtration rate; NT-proBNP - N-terminal pro B-type natriuretic peptide; ACEI - angiotensin converting enzyme inhibitors; ARB - angiotensin receptor blockers; BB — beta-adrenergic receptor blockers; ASA — acetylsalicylic acid; OAD — oral antidiabetic medication; HbA1c — glycated hemoglobin

did not meet the entry criteria. All 66 patients underwent successful PCI. The mean duration of DM was $6 \pm 3.2$ years. The mean $\mathrm{HbA1c}$ level of patients with DM was $6.8 \pm 0.9 \%$. The patient demographic and clinical characteristics are presented in Table 1.

\section{Angiographic data}

Patient angiographic characteristics are shown in Table 2. The mean EXTENT score was greater in patients with CAD and DM than in those with CAD only, but the differences were not statistically significant. There were no differences in SYNTAX score among diabetic and non-diabetic patients. In all patients who qualified for the study, complete revascularization of all coronary lesions qualified for PCI was performed. Thirty patients underwent two-step revascularization (16 with CAD, 14 with $\mathrm{CAD}$ and $\mathrm{DM})$. There was no difference in stent type used for revascularization between patients with or without DM. Second-generation drugeluting stents were mainly used (88\% and $89 \%$ for diabetic and non-diabetic patients, respectively).

\section{Echocardiographic data}

Two-dimensional echocardiography was performed in all 66 patients. LVEF, S', and Tei index were assessed in the whole group, while GLS was assessed in 53 patients. GLS was not assessed in 13 patients because anatomic conditions precluded the registration of an appropriate echocardiogram quality. Baseline echocardiographic parameters 
Table 2. Baseline angiographic characteristics.

\begin{tabular}{|c|c|c|c|}
\hline Parameter & $\begin{array}{c}\text { CAD + DM } \\
(n=34)\end{array}$ & $\begin{array}{c}\text { CAD } \\
(n=32)\end{array}$ & $\begin{array}{c}P \\
(C A D+D M \text { vs. CAD })\end{array}$ \\
\hline \multicolumn{4}{|l|}{ Stenotic coronary artery: } \\
\hline LAD & 8 & 9 & NS \\
\hline LCX & 3 & 3 & NS \\
\hline RCA & 7 & 6 & NS \\
\hline$L A D+R C A$ & 6 & 9 & NS \\
\hline$L A D+L C X$ & 7 & 3 & NS \\
\hline $\mathrm{LCX}+\mathrm{RCA}$ & 2 & 2 & NS \\
\hline $\mathrm{LAD}+\mathrm{LCX}+\mathrm{RCA}$ & 1 & 0 & NS \\
\hline \multicolumn{4}{|l|}{ EXTENT score: } \\
\hline Minimum, maximum & 3,90 & 3,58 & \\
\hline Median (Q1, Q3) & $24(6,43)$ & $17(12,32)$ & NS \\
\hline \multicolumn{4}{|l|}{ SYNTAX score: } \\
\hline Minimum, maximum & 2,39 & 2,34 & \\
\hline Median (Q1, Q3) & $9(6,16)$ & $10(6,18)$ & NS \\
\hline \multicolumn{4}{|l|}{ Stent type: } \\
\hline DES & $44(86 \%)$ & $37(79 \%)$ & NS \\
\hline BMS & $7(14 \%)$ & $10(21 \%)$ & NS \\
\hline Treated vessels per patient & 1.5 & 1.4 & NS \\
\hline
\end{tabular}

CAD - coronary artery disease; DM — diabetes mellitus type 2; LAD — left anterior descending artery; NS — statistically nonsignificant; LCX — left circumflex coronary artery; RCA — right coronary artery; DES — drug-eluting stents; BMS — bare metal stents

Table 3. Baseline echocardiographic parameters.

\begin{tabular}{lcccc}
\hline Parameter & $\begin{array}{c}\text { All patients } \\
(\mathbf{n}=\mathbf{6 6})\end{array}$ & $\begin{array}{c}\text { CAD + DM } \\
(\mathbf{n}=\mathbf{3 4 )}\end{array}$ & $\begin{array}{c}\text { CAD } \\
(\mathbf{n}=32)\end{array}$ & $\begin{array}{c}\text { P (CAD + DM } \\
\text { Vs. CAD) }\end{array}$ \\
\hline LVEDD [mm] & $44.7 \pm 5.4$ & $44.4 \pm 5.1$ & $45 \pm 5.7$ & NS \\
LVEDV [mL] & $85 \pm 21$ & $85 \pm 23$ & $85 \pm 18$ & NS \\
LVEF [\%] & $59 \pm 5$ & $58 \pm 4$ & $60 \pm 4$ & 0.028 \\
IVS [mm] & $11.1 \pm 1.4$ & $11.4 \pm 1.3$ & $10.8 \pm 1.4$ & NS \\
PW [mm] & $10.1 \pm 1.3$ & $10.2 \pm 1.4$ & $10 \pm 1.2$ & NS \\
LA [mm] & $33.3 \pm 3.7$ & $34 \pm 4.4$ & $32.7 \pm 2.7$ & NS \\
RV $[\mathrm{mm}]$ & $28.5 \pm 2.9$ & $28.9 \pm 2.9$ & $28 \pm 2.9$ & NS \\
E/A & $0.9 \pm 0.3$ & $0.9 \pm 0.3$ & $0.9 \pm 0.3$ & NS \\
DT [ms] & $262 \pm 72$ & $267 \pm 87$ & $257 \pm 52$ & NS \\
E' $[\mathrm{cm} / \mathrm{s}]$ & $8.1 \pm 1.4$ & $7.9 \pm 1.4$ & $8.4 \pm 1.4$ & NS \\
\hline
\end{tabular}

Data are presented as mean \pm standard deviation. CAD - coronary artery disease; DM — diabetes mellitus type 2; LVEDD — left ventricular end-diastolic diameter; NS - statistically nonsignificant; LVEDV - left ventricular end-diastolic volume; LVEF — left ventricular ejection fraction; IVS - intraventricular septum; PW - posterior wall; LA — left atrium; RV — right ventricle; E/A - ratio E/A (E, A waves - mitral inflow velocities); DT - E wave deceleration time; $E^{\prime}-$ mean early diastolic tissue velocity in the basal segments

before PCI are summarized in Table 3. LV function parameters differed between diabetic and non-diabetic patients. LVEF, GLS, and Tei index were significantly worse in diabetic patients before PCI (Table 4). All echocardiographic parameters of LV function improved significantly after PCI in all patients (Table 5). However, the differences in GLS and LVEF between the subgroups of patients with $\mathrm{CAD}$ and $\mathrm{DM}$ and those with $\mathrm{CAD}$ without $\mathrm{DM}$ were maintained (Table 4). GLS values increased by $18 \%$ in CAD patients and DM and by $14 \%$ in CAD patients without DM but were significantly 


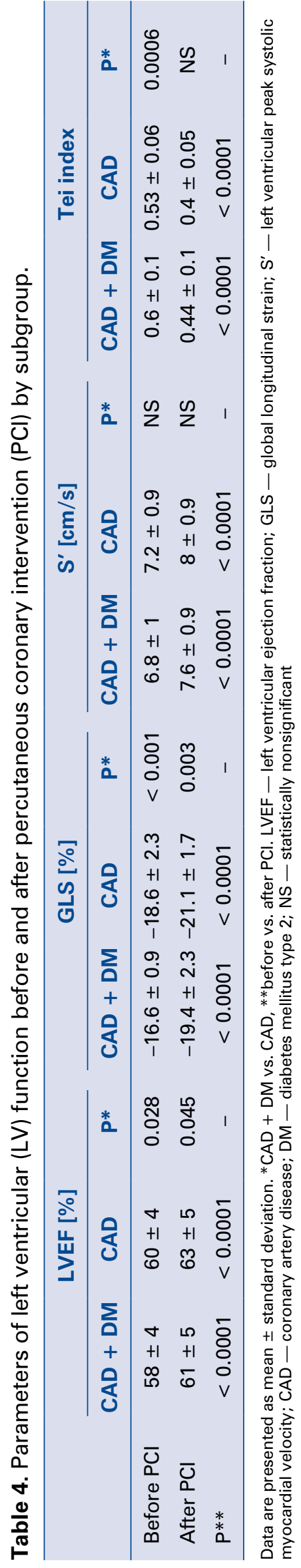

worse in diabetic patients than in non-diabetic patients $(\mathrm{p}=0.003)$.

There were high correlations between GLS and intraobserver and interobserver variation (correlation coefficient, 0.98 and 0.96 , respectively; $\mathrm{p}<0.001)$.

S' increased significantly after PCI in all patients (Tables 4 and 5). The range of S' changes was similar in both groups of patients (increase by $0.8 \mathrm{~cm} / \mathrm{s}$ ). Tei index improved significantly in all patients and in both subgroups of patients $(\mathrm{p}<$ $<0.0001$; Tables 4 and 5). The improvement in Tei index was more evident in patients with CAD and $\mathrm{DM}$ than in patients with CAD only $(-0.17 \pm 0.07$ vs. $-0.12 \pm 0.05$, respectively; $\mathrm{p}=0.002)$.

The average TLS for LAD, LCX, and RCA significantly improved after PCI (Table 6).

The patient group with one-vessel disease was also separated and the strain assessed before and after revascularization for territory distribution of this coronary artery and other LV segments. TLS after PCI increased in both territories $(-16.3 \pm$ $\pm 2.9 \%$ vs. $-19.7 \pm 2.6 \%$ and $-17.8 \pm 1.9 \%$ vs. $-19.6 \pm 2.2 \%$, respectively), but the change $(\Delta)$ was greater in the revascularized area $(\Delta-3.5 \pm$ $\pm 1.5 \%$ vs. $\Delta-1.8 \pm 1.5 \% ; \mathrm{p}=0.0001)$.

\section{Relationship between selected parameters and $\mathrm{LV}$ function}

Multivariate linear regression analyses were performed to evaluate the impact of selected factors on LV function after PCI are expressed as changes $(\Delta)$ of GLS, S', and Tei index. The selected factors included DM presence, DM duration, SYNTAX and EXTENT scores, sex, and age. The $\triangle$ GLS was associated with SYNTAX score. Higher SYNTAX scores were related to greater improvement in GLS and led to greater LV function improvement after revascularization $(\beta=0.003,95 \% \mathrm{CI} 0.0004-0.005$; $\mathrm{p}=0.02)$. No significant impacts of other variables on $\Delta \mathrm{GLS}$ or any tested factors on the $\Delta \mathrm{S}$ ' and the $\Delta$ Tei index were revealed.

\section{Discussion}

The present study showed that PCI significantly improved LV function in CAD patients with or without DM with preserved LVEF and no visual segmental wall motion abnormalities or heart failure symptoms. Advanced echocardiography with assessment of GLS, S', and Tei index enabled the diagnosis of subclinical impairment of LV systolic function in patients with stable CAD despite the absence of evident LV systolic dysfunction in con- 
Table 5. Parameters of left ventricular (LV) function before and after percutaneous coronary intervention (PCl) in all patients.

\begin{tabular}{|c|c|c|c|c|}
\hline & $\begin{array}{c}\text { LVEF [\%] } \\
(n=66)\end{array}$ & $\begin{array}{l}\text { GLS [\%] } \\
(n=53)\end{array}$ & $\begin{array}{l}S^{\prime}[\mathrm{cm} / \mathrm{s}] \\
(\mathrm{n}=66)\end{array}$ & $\begin{array}{c}\text { Tei index } \\
(n=66)\end{array}$ \\
\hline Before $\mathrm{PCl}$ & $59 \pm 5$ & $-17.5 \pm 2.34$ & $7.0 \pm 0.96$ & $0.57 \pm 0.09$ \\
\hline After PCl & $62 \pm 5$ & $-20.5 \pm 2.26$ & $7.8 \pm 0.95$ & $0.42 \pm 0.08$ \\
\hline $\mathrm{P}^{*}$ & 0.001 & 0.001 & 0.001 & 0.001 \\
\hline
\end{tabular}

Data are presented as mean \pm standard deviation. *Before vs. after PCI. LVEF — left ventricular ejection fraction; GLS — global longitudinal strain; $\mathrm{S}^{\prime}$ - left ventricular peak systolic myocardial velocity

Table 6. Territorial longitudinal strain (TLS) of the three major coronary arteries.

\begin{tabular}{lccc}
\hline & TLS before PCI [\%] & TLS after PCI & P* \\
\hline LAD & $-16.3 \pm 2.3$ & $-19.6 \pm 2.2$ & $<0.0001$ \\
LCX & $-16.9 \pm 2.7$ & $-19.8 \pm 2.7$ & 0.001 \\
RCA & $-16.8 \pm 3.3$ & $-20.3 \pm 2.6$ & $<0.0001$ \\
\hline
\end{tabular}

Data are presented as mean \pm standard deviation; *Before vs. after PCI. LAD — left anterior descending artery; LCX — left circumflex coronary artery; $\mathrm{PCl}$ - percutaneous coronary intervention; RCA — right coronary artery

ventional two-dimensional echocardiography and revealed LV functional improvement after PCI.

According to the literature, there are several mechanisms responsible for myocardial damage in patients with stable CAD. The most important are: reduced coronary flow, chronic ischemia [1], small-vessel microembolization, and endothelial dysfunction. Myocardial fibres consist of three different anatomical layers. The innermost subendocardial layer has an oblique clockwise orientation in the longitudinal direction. The subendocardial layer mainly contributes to cardiac long-axis function. Myocardial fibres of the subendocardial layer are more vulnerable to ischemic damage than those in the midmyocardium and subepicardium. Previous studies have demonstrated that, in the presence of the epicardial flow restriction, the subendocardial layer tends to have less blood flow than the subepicardial layer $[18,19]$. Choi et al. [20] suggested that repetitive ischemic episodes of LV myocardium due to significant coronary stenosis might reduce longitudinal function despite normal resting or a regional wall motion. This may explain why longitudinal measures such as GLS and S' are sensitive markers of ischemia and LV function impairments. Biering-Sorensen et al. [21] revealed differences between GLS values in patients with and without stable CAD and an LVEF $>50 \%$. GLS values were significantly lower in patients with $\geq 70 \%$ stenosis in at least one coronary artery compared to patients without coronary stenosis. Agarwal et al. [22] performed a systematic review and meta-analysis to assess the efficacy of tissue Doppler echocardiography indices in the diagnosis of CAD and demonstrated that LV S' was significantly decreased among patients with CAD compared to those without CAD. Ischemia is associated with a rapid and massive increase in the concentration of endogenous catecholamines in the myocardial interstitial fluid with a deleterious effect on cardiac myocytes culminating in myocardial apoptosis and fibrosis [23].

Limited data are available on the effects of PCI on LV function in patients with a preserved LVEF. The majority of studies examined the way in which PCI affects LV diastolic function or LV systolic function in patients with acute MI or complete coronary artery occlusion. In patients without a MI assessment of LV function after revascularization, testing was limited to the evaluation of $\mathrm{LV}$ contraction at rest and during dobutamine stress echocardiography or demonstrating enhanced performance in the exercise test [24,25].

In the present study, LV function was assessed simultaneously by four echocardiographic parameters: LVEF in the assessment of global LV function; GLS and S' in the assessment of systolic longitudinal function; and Tei index in the assessment of combined systolic and diastolic myocardial performance. This enabled a sensitive and comprehensive assessment of $\mathrm{LV}$ function before and after PCI. 
In all patients included in the study, GLS values were significantly higher after, than before PCI. There are limited data on GLS changes after elective PCI in patients with stable CAD and a preserved LVEF. Ryo et al. [26] showed LV function improvements expressed as GLS in 35 patients 1 month after PCI. Antoni et al. [17] assessed LV function after acute MI using GLS during 1 year of follow-up. Patients with an increase in GLS $\geq$ $10 \%$ are recognized as improvers. In the present study, the increase in GLS after PCI was $17 \%$ in all groups of patients despite their lack of MI and having less LV dysfunction.

Percutaneous coronary intervention significantly improved S' values in all patients. Diller et al. [8] studied 24 patients with normal systolic LV function undergoing elective PCI and showed that $\mathrm{S}$ ' improved in all investigated ventricular areas compared to pre-interventional values. Surucu et al. [27] did not found any improvement in S' values after revascularization. These differences may be due to different time spans between PCI and the re-assessment of S' in the present study.

Another important finding was that PCI significantly reduced the Tei index. A change in the Tei index was more beneficial in diabetic patients with CAD than in patients with CAD only. The data of Tei index before and after elective PCI are scarce and limited to patients with MI. According to available research, the Tei index has not been used to assess $\mathrm{LV}$ function changes after revascularization in cases of stable CAD. The improvement in TLS confirms the beneficial effect of PCI on LV function in patients with stable CAD and a preserved LVEF.

Tei index, LVEF, and GLS values before PCI were worse in patients with CAD and DM compared to patients with CAD only despite the lack of statistically significant differences in the extent of atherosclerosis in the coronary arteries assessed using SYNTAX and EXTENT scores. This finding is in accordance with the hypotheses of increased myocardial stiffness, increased resting myocyte tension, and the deposition of advanced glycated end products associated with diabetic cardiomyopathy and worse systolic and diastolic LV function in diabetic patients [28].

The improvement of LV function after PCI observed in the current study was similar in nondiabetic and diabetic patients. However, LVEF and GLS values were still worse after PCI in patients with $\mathrm{CAD}$ and $\mathrm{DM}$ compared to those with $\mathrm{CAD}$ but without DM. This may suggest that PCI improved LV function similarly in all patients enrolled in the study and differences resulted from worse baseline LV function in patients with DM.

In the present study, higher SYNTAX scores were associated with greater improvement in GLS. According to available research, this is a new finding. SYNTAX score is considered a parameter of anatomical CAD complexity; therefore, it could be used as an indirect marker of plaque burden [29]. A greater plaque burden indicated by a higher SYNTAX score may lead to a more beneficial effect of complete revascularization in this group of patients.

The improvement of LV function noted in the present study may have clinical consequences i.e., reduced future heart failure. This paper opens the door to future investigations assessing the importance of small but detectable LV function changes in patients with and without DM.

\section{Limitations of the study}

The current study has some limitations. First, the number of patients enrolled is relatively small. Second, the severity of atherosclerosis in the coronary arteries was assessed by one investigator. And finally, SYNTAX and EXTENT scores are subjective [30].

\section{Conclusions}

Percutaneous coronary intervention significantly improved LV function in diabetic and nondiabetic CAD patients with a preserved LVEF. Enhanced echocardiography allows the assessment of subtle beneficial changes in LV function in patients with no wall motion visual abnormalities, i.e. candidates for PCI. These results support the indication for PCI in diabetic and non-diabetic patients.

\section{Acknowledgments}

The study was supported by research grant 501-2-1-09-38 from the Center of Postgraduate Medical Education, Warsaw, Poland.

Conflict of interest: None declared

\section{References}

1. Gheorghiade M, Sopko G, De Luca L, et al. Navigating the crossroads of coronary artery disease and heart failure. Circulation. 2006; 114(11): 1202-1213, doi: 10.1161/CIRCULATIONAHA.106.623199, indexed in Pubmed: 16966596.

2. Montalescot G, Sechtem U, Achenbach S, et al. 2013 ESC guidelines on the management of stable coronary artery disease: the Task Force on the management of stable coronary artery 
disease of the European Society of Cardiology. Eur Heart J. 2013; 34(38): 2949-3003, doi: 10.1093/eurheartj/eht296, indexed in Pubmed: 23996286.

3. Windecker S, Stortecky S, Stefanini GG, et al. Revascularisation versus medical treatment in patients with stable coronary artery disease: network meta-analysis. BMJ. 2014; 348: g3859, doi: 10.1136/bmj.g3859, indexed in Pubmed: 24958153.

4. Li X, Kong M, Jiang D, et al. Comparing coronary artery bypass grafting with drug-eluting stenting in patients with diabetes mellitus and multivessel coronary artery disease: a meta-analysis. Interact Cardiovasc Thorac Surg. 2014; 18(3): 347-354, doi: 10.1093/icvts/ivt509, indexed in Pubmed: 24345688.

5. Dai X, Luo ZC, Zhai Lu, et al. Reassessing Coronary Artery Bypass Surgery Versus Percutaneous Coronary Intervention in Patients with Type 2 Diabetes Mellitus: A Brief Updated Analytical Report (2015-2017). Diabetes Ther. 2018; 9(5): 2163-2171, doi: 10.1007/s13300-018-0504-3, indexed in Pubmed: 30220039.

6. Strotmann JM, Richter A, Kukulski T, et al. Doppler myocardial imaging in the assessment of regional myocardial function in longitudinal direction pre- and post-PTCA. Eur J Echocardiogr. 2001; 2(3): 178-186, doi: 10.1053/euje.2001.0091, indexed in Pubmed: 11882451.

7. Labovitz AJ, Lewen M, Kern MJ, et al. The effects of successful PTCA on left ventricular function: assessment by exercise echocardiography. Am Heart J. 1989; 117(5): 1003-1008, indexed in Pubmed: 2523633.

8. Diller GP, Wasan BS, Thom SA, et al. Evidence of improved regional myocardial function in patients with chronic stable angina and apparent normal ventricular function--a tissue Doppler study before and after percutaneous coronary intervention. J Am Soc Echocardiogr. 2009; 22(2): 177-182, doi: 10.1016/j. echo.2008.10.018, indexed in Pubmed: 19022622.

9. Gasior Z, Drzewiecki J, Wita K, et al. [Left ventricular systolic function after PTCA--recent and late assessment by exercise echocardiography]. Pol Arch Med Wewn. 1994; 92(4): 307-312, indexed in Pubmed: 7854958.

10. Smith SC, Feldman TE, Hirshfeld JW, et al. ACC/AHA/SCAI 2005 guideline update for percutaneous coronary intervention. A report of the American College of Cardiology/American Heart Association Task Force on practice guidelines (ACC/AHA/SCAI Writing Committee to Update the 2001 Guidelines for Percutaneous Coronary Intervention). Circulation. 2006; 113(7): e166-286.

11. Sianos G, Morel MA, Kappetein AP, et al. The SYNTAX Score: an angiographic tool grading the complexity of coronary artery disease. EuroIntervention. 2005; 1(2): 219-227, indexed in Pubmed: 19758907.

12. Sullivan DR, Marwick TH, Freedman SB. A new method of scoring coronary angiograms to reflect extent of coronary atherosclerosis and improve correlation with major risk factors. Am Heart J. 1990; 119(6): 1262-1267, indexed in Pubmed: 1972310.

13. Tei C. New non-invasive index for combined systolic and diastolic ventricular function. J Cardiol. 1995; 26(2): 135-136, indexed in Pubmed: 7674144.

14. Schiller NB, Shah PM, Crawford M, et al. Recommendations for quantitation of the left ventricle by two-dimensional echocardiography. American Society of Echocardiography Committee on Standards, Subcommittee on Quantitation of Two-Dimensional Echocardiograms. J Am Soc Echocardiogr. 1989; 2(5): 358-367, indexed in Pubmed: 2698218.

15. Lang RM, Badano LP, Mor-Avi V, et al. Recommendations for cardiac chamber quantification by echocardiography in adults: an update from the American Society of Echocardiography and the European Association of Cardiovascular Imaging. J Am Soc Echocardiogr. 2015; 28(1): 1-39.e14, doi: 10.1016/j. echo.2014.10.003, indexed in Pubmed: 25559473.

16. Nakai H, Takeuchi M, Nishikage T, et al. Subclinical left ventricular dysfunction in asymptomatic diabetic patients assessed by two-dimensional speckle tracking echocardiography: corre- lation with diabetic duration. Eur J Echocardiogr. 2009; 10(8): 926-932, doi: 10.1093/ejechocard/jep097, indexed in Pubmed: 19622532.

17. Antoni ML, Mollema SA, Atary JZ, et al. Time course of global left ventricular strain after acute myocardial infarction. Eur Heart J. 2010; 31(16): 2006-2013, doi: 10.1093/eurheartj/ehq198, indexed in Pubmed: 20566488.

18. Bache RJ, McHale PA, Greenfield JC. Transmural myocardial perfusion during restricted coronary inflow in the awake dog. Am J Physiol. 1977; 232(6): H645-H651, doi: 10.1152/ ajpheart.1977.232.6.H645, indexed in Pubmed: 879303.

19. Yao GH, Zhang C, Sun FR, et al. Quantification of transmural gradient of blood flow in myocardial ischemia with real-time myocardial contrast echocardiography and dipyridamole stress test. Ultrasound Med Biol. 2008; 34(1): 22-30, doi: 10.1016/j. ultrasmedbio.2007.06.019, indexed in Pubmed: 17854984.

20. Choi JO, Cho SW, Song YB, et al. Longitudinal 2D strain at rest predicts the presence of left main and three vessel coronary artery disease in patients without regional wall motion abnormality. Eur J Echocardiogr. 2009; 10(5): 695-701, doi: 10.1093/ ejechocard/jep041, indexed in Pubmed: 19401300.

21. Biering-Sørensen T, Hoffmann S, Mogelvang R, et al. Myocardial strain analysis by 2-dimensional speckle tracking echocardiography improves diagnostics of coronary artery stenosis in stable angina pectoris. Circ Cardiovasc Imaging. 2014; 7(1): 58-65, doi: 10.1161/CIRCIMAGING.113.000989, indexed in Pubmed: 24186963.

22. Agarwal R, Gosain P, Kirkpatrick JN, et al. Tissue Doppler imaging for diagnosis of coronary artery disease: a systematic review and meta-analysis. Cardiovasc Ultrasound. 2012; 10: 47, doi: 10.1186/1476-7120-10-47, indexed in Pubmed: 23199010.

23. Tomai F, Crea F, Chiariello L, et al. Ischemic preconditioning in humans: models, mediators, and clinical relevance. Circulation. 1999; 100(5): 559-563, indexed in Pubmed: 10430772.

24. Klisiewicz A, Michałek P, Szymański P, et al. Changes in the response of hibernated myocardium to inotropic stimulation after angioplasty: a Doppler myocardial imaging study. Clin Cardiol. 2003; 26(11): 503-507, doi: 10.1002/clc.4960261105, indexed in Pubmed: 14640464.

25. Parisi AF, Folland ED, Hartigan P. A comparison of angioplasty with medical therapy in the treatment of single-vessel coronary artery disease. Veterans Affairs ACME Investigators. N Engl J Med. 1992; 326(1): 10-16, doi: 10.1056/NEJM199201023260102, indexed in Pubmed: 1345754.

26. Ryo K, Tanaka H, Kaneko A, et al. Efficacy of longitudinal speckle tracking strain in conjunction with isometric handgrip stress test for detection of ischemic myocardial segments. Echocardiography. 2012; 29(4): 411-418, doi: 10.1111/j.15408175.2011.01621.x, indexed in Pubmed: 22329730.

27. Sürücü H, Tatli E, Okudan S, et al. Evaluation of subendocardial and subepicardial left ventricular functions using tissue Doppler imaging after complete revascularization. Echocardiography. 2009; 26(2): 203-210, doi: 10.1111/j.1540-8175.2008.00765.x, indexed in Pubmed: 19054027.

28. Aneja A, Tang WH, Bansilal S, et al. Diabetic cardiomyopathy: insights into pathogenesis, diagnostic challenges, and therapeutic options. Am J Med. 2008; 121(9): 748-757, doi: 10.1016/j. amjmed.2008.03.046, indexed in Pubmed: 18724960.

29. Stuart HJ, Farooq V, Serruys PW, et al. The SYNTAX score and its clinical implications. Heart. 2014; 100(2): 169-177, doi: 10.1136/ heartjnl-2012-302482, indexed in Pubmed: 23539552.

30. Généreux P, Palmerini T, Caixeta A, et al. SYNTAX score reproducibility and variability between interventional cardiologists, core laboratory technicians, and quantitative coronary measurements. Circ Cardiovasc Interv. 2011; 4(6): 553-561, doi: 10.1161/CIRCINTERVENTIONS.111.961862, indexed in Pubmed: 22028472. 